\title{
Dopaminergic Reduction of Excitability in Nucleus Accumbens Neurons Recorded in Vitro
}

\author{
Patricio O'Donnell, M.D., Ph.D., and Anthony A. Grace, Ph.D.
}

Dopanine (DA) receptor actioation has been shown to affect the striatal complex in a multidimensional manner. However, the question of whether its net effect on postsynaptic targets in the nucleus accumbens and striatum is excitatory or inhibitory in nature has been a topic of controversy for some time. This study focuses on the effects of DA agonists on indices of postsynaptic cell mentbrane excitability in nucleus accumbens neurons, such as the amount of intracellular current injection required to elicit spike firing and the membrane potential at which action potentials are evoked. Administration of the nonspecific $D_{1} \mathrm{D}_{2}$ DA agonist apomorphine induced a membrane depolarization that was not mimicked by the $D_{1}$ agonist

KEY WORDS: Strintum; Electrophysiology; Intracellular recording; Dopamine; Apomorphine, Nucleus accumbens

The nucleus accumbens comprises the limbic aspect of the striatal complex, and it is a component within several parallel circuits involved in basal ganglia function (Alexander and Crutcher 1990). Most of the afferents to the accumbens arise within limbic cortical and subcortical areas, such as the amygdala, hippocampus, and prefrontal cortex (Groenewegen et al. 1980; Sesack et al.

From the Departments of Neuroscience and Psychiatry, Center for Neuroscience, Lniversity of l'ittsburgh, Pittsburgh, PA.

Address correspondence to Patricio O'Donnell, M.D., Ph.D., Department of Neuroscience, University of Pittsburgh, Pittsburgh, PA 15260 .

Received April 3, 1995; revised August 16, 1995; accepted September 14, 1995 .
SKF 38393, by the $D_{2}$ agonist quinpirole, or by the combined administration of both drugs. On the other hand, subsets of neurons responded to apomorphine or combined $D_{1} D_{2}$ agonist administration with a response that reversed near $-90 \mathrm{mV}$. Following the administration of apomorphine or the combined administration of the $D_{1}$ and $D_{2}$ agonists, nucleus accumbens neurons required significantly higher amplitudes of depolarizing current injection to elicit spike firing. These results suggest that coactivation of $D_{1}$ and $D_{2}$ receptors on accumbens neurons causes a reduction in their membrane excitability.

[Neuropsychopharmacology 15:87-97, 1996]

1989). In turn, the nucleus accumbens can affect limbic system activity via its output through the ventral pallidum (Heimer et al. 1991) to the thalamic mediodorsal nucleus (Lavin and Grace 1994; Young et al. 1984), which in turn projects to the prefrontal cortex (Uylings and van Eden 1990). Based on differences in neurochemistry and connectivity, the accumbens has been subdivided into two major compartments: the area surrounding the anterior commissure known as the core, and the ventral and medial aspects of the accumbens that have been termed the shell (Heimer et al. 1991; Paxinos and Watson 1986; Záborszky et al. 1985). Although core cells are considered striatal-like in function and neurons in the shell region are believed to be part of the extended amygdala (Alheid and Heimer 1988), we have recently demonstrated that, aside from a few specific physiological differences, neurons in both regions exhibit primarily striatal-like morphological and electro- 
physiological characteristics (O'Donnell and Grace 1993b).

The nucleus accumbens is gaining increasing attention as a result of data suggesting that dopamine (DA) transmission within this region is involved in the etiology and treatment of schizophrenia and other neuropsychiatric disorders (Snyder 1973; Chiodo and Bunney 1983; Grace 1991). However, the precise nature in which DA affects accumbens neuron physiology has not been established. Indeed, the actions of DA in the accumbens, as in the striatal complex in general, have remained the subject of controversy for some time. Thus, dopaminergic effects on striatal and accumbens medium spiny neurons were initially characterized as inhibitory in nature (Connor 1970; McLennan and York 1976), although several investigators had challenged this concept (Kitai et al. 1976). Moreover, studies utilizing intracellular recording techniques have reported both depolarizing and hyperpolarizing responses to DA that appeared to be dependent on such factors as the dopamine concentration or firing status of the neuron recorded (Herrling and Hull 1980; Uchimura et al. 1986; Akaike et al. 1987). In most studies employing extracellular recording approaches, iontophoretic application of DA or stimulation of the substantia nigra was consistently found to inhibit striatal or accumbens cell activity (Connor 1970; Woodruff et al., 1976; Brown and Arbuthnott 1983; White and Wang 1986; Ohno et al. 1987; Hu and Wang 1988). Although there are also reports of subsets of cells showing an increase in activity after stimulation of the substantia nigra (Connor 1970; Kitai et al. 1976), based on the rapid onset of the evoked responses these excitatory events appeared to involve the activation of a fast-conducting pathway, such as the corticospinal fibers traversing the pedunculus (Connor 1970) or a nondopaminergic nigrostriatal neuron type (Guyenet and Aghajanian 1978).

There are several studies of DA actions on membrane potential, firing rate, synaptic responses, and electrotonic transmission between neurons in the nucleus accumbens (Woodruff et al. 1976; De France et al. 1985; Uchimura et al. 1986; White and Wang 1986; Mogenson et al. 1988; O'Donnell and Grace 1993a, 1994; Pennartz et al. 1992a, b); nonetheless, the multiplicity of its actions has complicated our understanding of the overall effects of DA on striatal cell activity. A different approach to interpreting the actions of DA on nucleus accumbens neuronal membrane properties may be derived from a consideration of its relevance to the information processing function of this structure. The aim of this study was to assess the effects of DA agonists on the excitability of neurons in the core and shell regions of the nucleus accumbens as it relates to the interaction between membrane potential and cell excitability using an in vitro rat brain slice preparation (O'Donnell and Grace 1993b).

\section{MATERIALS AND METHODS}

Intracellular recordings were performed from neurons located in the nucleus accumbens of rat brain slices maintained in vitro. Adult male Sprague-Dawley rats (190-340 g) obtained from Zivic-Miller laboratories (Allison Park, PA) were used in this study. All procedures were performed in accordance with the Guide for the Care and Use of Laboratory Animals published by the USPHS, and the experimental protocol was approved by the University of Pittsburgh Animal Care and Use Committee. Experimental details are outlined elsewhere (O'Donnell and Grace 1993b). Briefly, rats were deeply anesthetized with chloral hydrate $(400 \mathrm{mg} / \mathrm{kg})$ before decapitation. The brain was rapidly removed and $4 \mathrm{~mm}$ parasagittal blocks containing the nucleus accumbens were made using a rat brain matrix (Activation Systems RBM-4000S). The blocks were placed in ice-cold physiological saline solution containing $124 \mathrm{mM} \mathrm{NaCl}, 5 \mathrm{mM}$ $\mathrm{KCl}, 1.2 \mathrm{mM} \mathrm{KH}_{2} \mathrm{PO}_{4}, 2.4 \mathrm{mM} \mathrm{CaCl}, 1.3 \mathrm{mM} \mathrm{MgSO}$, $26 \mathrm{mM} \mathrm{NaHCO}$, and $10 \mathrm{mM}$ glucose, and saturated with $95 \%: 5 \% \quad \mathrm{O}_{2}: \mathrm{CO}_{2}$ before sectioning into $400-\mu \mathrm{m}$ thick slices using a Vibratome (Vibratome ${ }^{\circledR}$ series 1000 ). The sections were incubated at room temperature in continuously oxygenated physiological saline for at least 1 hour. The slices were then placed into a submersion-type recording chamber maintained at 33 to $35^{\circ} \mathrm{C}$ and superfused with oxygenated physiological saline solution at a flow rate of 1 to $2 \mathrm{ml} /$ minute controlled by a peristaltic pump (Haake-Büchler, model MCP 2500). The time required to completely change the media within the chamber at this rate was 2 to 4 minutes (O'Donnell and Grace 1993b).

Electrodes were constructed from $1 \mathrm{~mm}$ OD Omegadot (WPI, Sarasota, FL) borosilicate glass tubing using a Flaming-Brown P-80/PC electrode puller. The electrodes were filled with $3 \mathrm{mM}$ potassium acetate (electrode resistance: 60 to $120 \mathrm{M} \Omega$ measured in situ). Recording electrodes were lowered into the core or the shell region of the nucleus accumbens. These areas were identified using a stereomicroscope (Nikon SMZ-2B) according to a rat brain stereotaxic atlas (Paxinos and Watson 1986). The anterior commissure, striatum, septum, and subcortical white matter were used as landmarks to guide electrode placement.

The signals collected by the electrode were amplified using a headstage located near the preparation and connected to an intracellular preamplifier (Neurodata IR183). Current was injected into the neurons across an active bridge circuit integral to the preamplifier, and the amplitude of the current injected and the electrode potential were monitored on a storage oscilloscope (Kikusui COS 5020-ST). Custom-designed software (Neuroscope) running on a workstation (Apollo series 400, Hewlett-Packard) containing a Microstar (Microstar Laboratories, Bellevue, WA) interface board was 
employed for triggering the stimulator and storage of the signals for off-line analysis. The bridge balance was continuously monitored during the entire recording procedure, and any variation was immediately compensated by adjusting the bridge.

After obtaining stable baseline data for at least $5 \mathrm{~min}$ utes, the perfusion lines leading into the peristaltic pump were switched to allow perfusion with the drug-containing media, thus maintaining a stable perfusion pressure and volume. The drugs used were apomorphine (Sigma, St. Louis, MO; 10-150 $\mu \mathrm{M}$ ), quinpirole (Research Biochemicals Inc., RBI, Nattick, MA; $1-10 \mu \mathrm{M}$ ), and SKF 38393 (RBI, 3-10 $\mu \mathrm{M}$ ). Stock solutions of the drugs were prepared by dissolving them in distilled water, with the working solutions prepared on the day of use by diluting appropriate amounts of these stock solutions into physiological saline. Ascorbic acid $(0.02 \%)$ was added to prevent oxidation of apomorphine. To rule out any potential confounds related to the physiological actions of ascorbic acid, both control and drug-containing solutions contained the antioxidant. For statistical comparisons the paired Student's $t$ test was employed. Although $\alpha$ was set at $p<.05$, it was adjusted according to a Bonferroni correction for multiple comparisons on a given data set. All data are expressed as mean \pm SD.

\section{RESULTS}

A total of 45 cells were recorded in slices obtained from 31 animals. The recordings were obtained from neurons located in the core and the shell regions of the accumbens. Since the results obtained from cells in each region were similar (with the exceptions noted later), the data obtained from neurons located in both regions were pooled. In control conditions, intrinsic membrane properties of accumbens cells were identical to those we had reported previously using a similar preparation (O'Donnell and Grace 1993b). Neurons located in the nucleus accumbens had an average resting membrane potential (RMP) of $-70.6 \pm 7.7 \mathrm{mV}$ (mean $\pm \mathrm{SD}$; range: -54 to $-89 \mathrm{mV}, n=45)$. The input resistance was $55.2 \pm$ $23.6 \mathrm{M} \Omega(22.6$ to $129.4 \mathrm{M} \Omega, n=44)$, and the time constant $(\tau)$ was $6.9 \pm 2.6 \mathrm{~ms}$ ( 3.2 to $12.0 \mathrm{~ms} ; n=23$ ).

\section{Dopamine Agonist Effects on Passive Membrane Properties of Accumbens Neurons}

Upon perfusion with apomorphine, the majority of cells sampled (23 out of 26) exhibited a membrane depolarization. The cells depolarized from a RMP of $-68.8 \pm$ $8.3 \mathrm{mV}(-54$ to $-80 \mathrm{mV})$ to $-57.3 \pm 10.5 \mathrm{mV}(-40$ to $-72 \mathrm{mV} ; n=26 ; \mathrm{p}<.0001$ compared to control conditions, paired Student's $t$ test, $t=6.2$; Figure 1A), which was followed by a slow return to control values after washout of apomorphine (30 minute washout: $-68.2 \pm$
$7.2 \mathrm{mV}$; range: -57 to $-78 \mathrm{mV} ; n=9$; Figure $1 \mathrm{~A}, \mathrm{~B})$. The average membrane depolarization produced by apomorphine administration was $11.9 \pm 10.0 \mathrm{mV}$ and was produced in a dose-dependent manner $(r=0.60$; regression $F$ ratio $=13.21 ;$ df: 1,$24 ; p<.001 ;$ Figure 2A). These changes in membrane potential occurred without a corresponding change in the average input resistance (Figure $1 \mathrm{C})$, which was $59.6 \pm 25.2 \mathrm{M} \Omega(23.1$ to $129.4 \mathrm{M} \Omega$ ) in control conditions and $57.8 \pm 28.4 \mathrm{M} \Omega(15.9$ to 121.5 $\mathrm{M} \Omega, n=26)$ during perfusion with apomorphine. Thus, the average input resistance during apomorphine perfusion was $99.9 \pm 44.6 \%$ of predrug values, and the net change across each cell tested was $-0.4 \pm 24.4 \mathrm{M} \Omega$. However, a subset of neurons $(5 / 23)$ did exhibit substantial alterations in input resistance in addition to a membrane depolarization in response to apomorphine administration. When this subset of cells was analyzed separately, the response was found to exhibit a reversal potential of $-95.3 \pm 11.8 \mathrm{mV}(n=5)$ as determined by their current voltage (LV) plot. No change in $\tau$ was observed in response to apomorphine administration, measuring $7.8 \pm 2.1 \mathrm{~ms}$ before and $7.1 \pm 0.9 \mathrm{~ms}$ during perfusion with this DA agonist $(n=13)$.

Administration of the selective $\mathrm{D}_{1}$ agonist SKF 38393 (3-10 $\mu \mathrm{M})$ or the $\mathrm{D}_{2}-\mathrm{D}_{3}$ agonist quinpirole $(1-10 \mu \mathrm{M})$ did not alter the RMP, input resistance, or $\tau$ of accum-

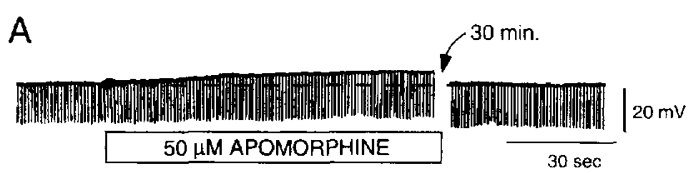

B

$\mathrm{C}$

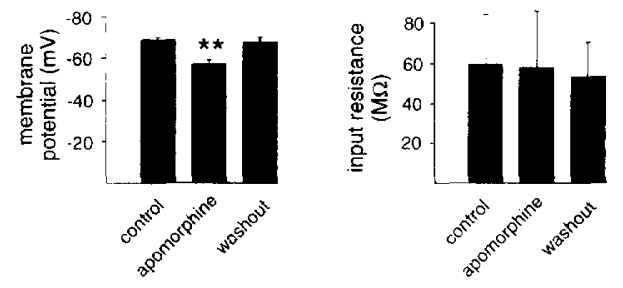

Figure 1. Perfusion with the $D_{1} / D_{2}$ DA agonist apomorphine induces a change in resting membrane potential, but not in input resistance, of accumbens cells. (A) The steadystate membrane potential (horizontal line) and the relative input resistance (vertical deflections produced by $-0.25 \mathrm{nA}$ current pulses) of an accumbens neuron recorded during administration of $50 \mu \mathrm{M}$ apomorphine (open bar below trace). Perfusion with apomorphine resulted in an $8 \mathrm{mV}$ depolarization of the membrane relative to resting values (dashed line) without producing a significant change in the input resistance. After a 30-minute period of drug washout (break in trace at arrow), the membrane potential returns to control values. (B) Membrane potential and (C) input resistance values before (control), during, and after (washout) administration of $10-150 \mu \mathrm{M}$ apomorphine. ${ }^{* *} p<.0001$, paired Student's $t$ test. 

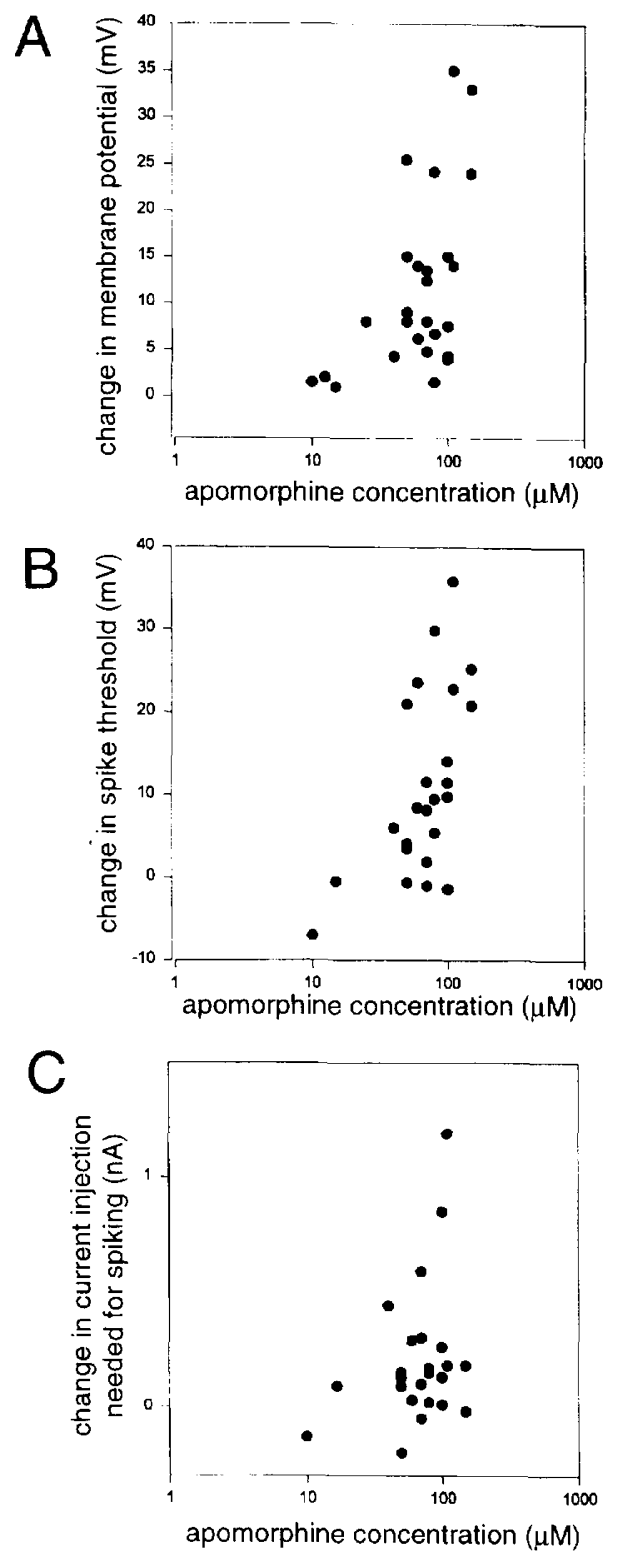

Figure 2. Most of the effects produced by apomorphine on accumbens neurons are dose-dependent. (A) The membrane depolarizations observed in cells located in the nucleus accumbens are plotted against the concentration of apomorphine administered. Larger depolarizations are observed with higher concentrations of apomorphine $(r=0.60 ; p<$ .001). (B) Similarly, larger changes in spike threshold are observed with larger apomorphine doses $(r=0.52 ; p<.01)$. (C) The current injection required to elicit action potential firing was increased upon administration of apomorphine in the perfusion fluid, although the magnitude of this effect was not linearly related to the dose of apomorphine administered $(r=0.15 ; p>$.4).

bens neurons when analyzed as a single group (Table 1). Furthermore, perfusion with both the $D_{1}$ agonist and the $\mathrm{D}_{2}$ agonist simultaneously also failed to yield significant changes in the membrane potential, input resis- tance, or $\tau$ of the accumbens neurons studied ( $n=5$; Table 1 ). However, as found with apomorphine administration, a subset of these cells ( 2 out of 5 ) exhibited both a membrane depolarization and an increase in input resistance, with reversal potentials of -91 and $-88 \mathrm{mV}$.

\section{Dopamine Agonist Effects on Spike Discharge Properties}

Although none of the nucleus accumbens neurons recorded exhibited spontaneous spike discharge, spikes could be evoked by intracellular injection of depolarizing current. The threshold level of current injection required to elicit spike discharge in $50 \%$ of trials averaged $0.32 \pm 0.20 \mathrm{nA}$ (range: 0.06 to $0.76 \mathrm{nA} ; n=42$ ) in the population of accumbens neurons tested. Action potentials were elicited when the membrane potential reached a threshold value of $-42.3 \pm 9.0 \mathrm{mV}$ (range: -22.8 to $-73.1 \mathrm{mV} ; n=42$ ). The action potential threshold was found to correlate with the resting membrane potential of the cell $(r=0.49$; regression $F$ ratio $=5.99$; df: 1,23 ; $p<.03$; Figure 3A), although this relationship accounted for less than $25 \%$ of the variance $\left(r^{2}=0.24\right)$. As described previously (O'Donnell and Grace 1993b), spikes were preceded by a slow depolarization (Figures $4 \mathrm{~A}, 5 \mathrm{~A}, \mathrm{~B}$ ) that was observed as an inward rectification in the depolarizing direction in $\mathrm{L} / \mathrm{V}$ plots (Figures $4 \mathrm{~B}$, 5D). Perfusion of the slice with apomorphine prevented the occurrence of the slow depolarization preceding spikes in $77 \%$ (10 out of 13 ) of the neurons studied in the core region (Figure 5), but failed to block similar depolarizations in any of the four cells that exhibited this potential in the shell region (Figure 4).

After perfusion with apomorphine, the membrane potential corresponding to spike threshold was shifted to more depolarized values in most cells recorded (Figures $4,6 \mathrm{~A}$ ). The membrane potential at which cells fired during intracellular current injection shifted from $-44.2 \pm$ $8.2 \mathrm{mV}(-32.5$ to $-73.1 \mathrm{mV})$ in control conditions to $-33.6 \pm 13.1 \mathrm{mV}(-10$ to $-59 \mathrm{mV})$ in the presence of apomorphine $(n=22, t=4.9, p<.0001$; average change in threshold: $10.6 \pm 10.7 \mathrm{mV}$ ). These actions were not a consequence of nonspecific membrane effects of the drug because the action potentials elicited in both control and drug perfusion conditions reached similar peak values (upper dashed line in Figure 4). Furthermore, significantly larger amplitudes of current injection were required in order to induce spike discharge following apomorphine (control: $0.28 \pm 0.18 \mathrm{nA}$, apomorphine: $0.49 \pm 0.32 \mathrm{nA}, n=25 ; t=3.5 ; p<.005$; Figure 6B). After washout of the drug for 20 to 30 minutes, the spike threshold returned to control levels: spikes were again elicited at a membrane potential of $-40.0 \pm 5.3 \mathrm{mV}$ $(-32.8$ to $-45.2 \mathrm{mV} ; n=9)$ and by current injection amplitudes of $0.35 \pm 0.13 \mathrm{nA}$ or greater $(0.19$ to $0.62 \mathrm{nA}$, $n=9$ ). There was a significant correlation between these 

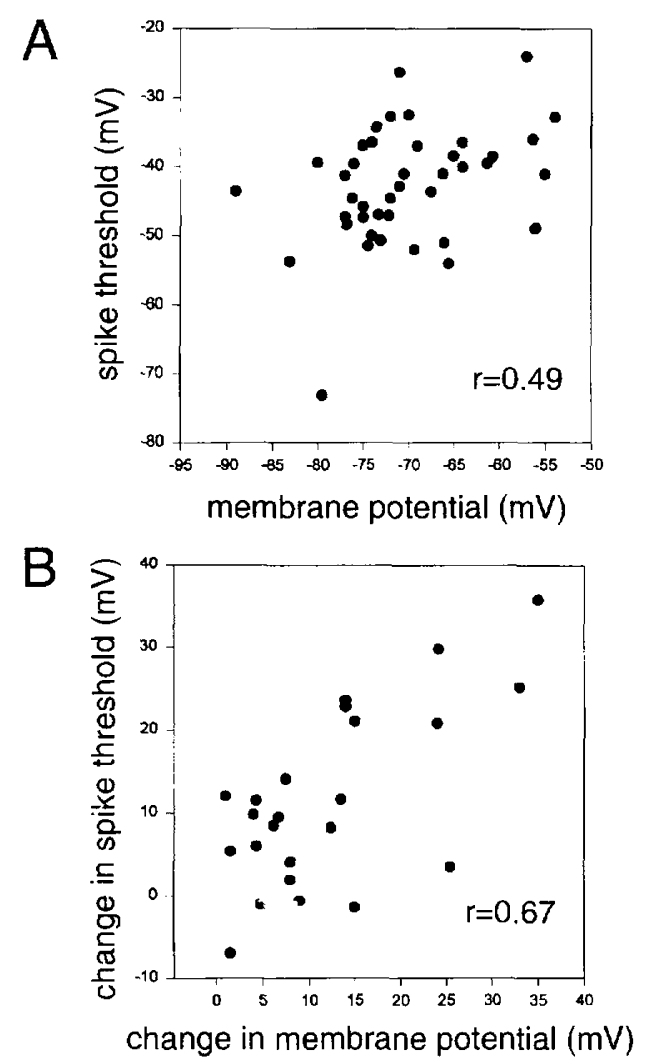

Figure 3. Relationship between membrane potential and spike threshold and their alteration by apomorphine administration. (A) Spike threshold is plotted against the basal membrane potential for each cell. In the control state, there was a small but significant correlation between RMP and spike threshold $(r=0.49 ; p<.03)$. (B) In contrast, the change in spike threshold induced by apomorphine shows a higher level of correlation with the magnitude of membrane depolarization induced by this drug $(r=0.67 ; p<.001)$.

changes in threshold and the degree of membrane depolarization observed in accumbens neurons treated with apomorphine $(r=0.67$; regression $F$ ratio $=18.32$; df: 1,$22 ; p<.0001$; Figure 3B), and the correlation was dose dependent $(r=0.52$; regression $F$ ratio $=8.1$; df: 1,$22 ; p<.01$; Figure $2 \mathrm{~B}$ ). However, the effects of apomorphine on the amplitude of intracellular current injection required to elicit spike firing were not correlated with the concentration of the drug administered $(r=$ 0.15 ; regression $F$ ratio $=0.51 ;$ df: 1,22 ; Figure $2 \mathrm{C}$ ).

Perfusion with the $\mathrm{D}_{2}$ agonist quinpirole alone did not result in changes in spike threshold, nor did it change the threshold amplitude of current injection necessary to induce spike discharge (Table 2). Similarly, administration of the $\mathrm{D}_{1}$ agonist SKF 38393 did not change either the amplitude of current injection required to reach spike threshold or the membrane potential corresponding to spike threshold (Table 2). Although simultaneous administration of the selective $D_{1}$ and $D_{2}$ ago- 


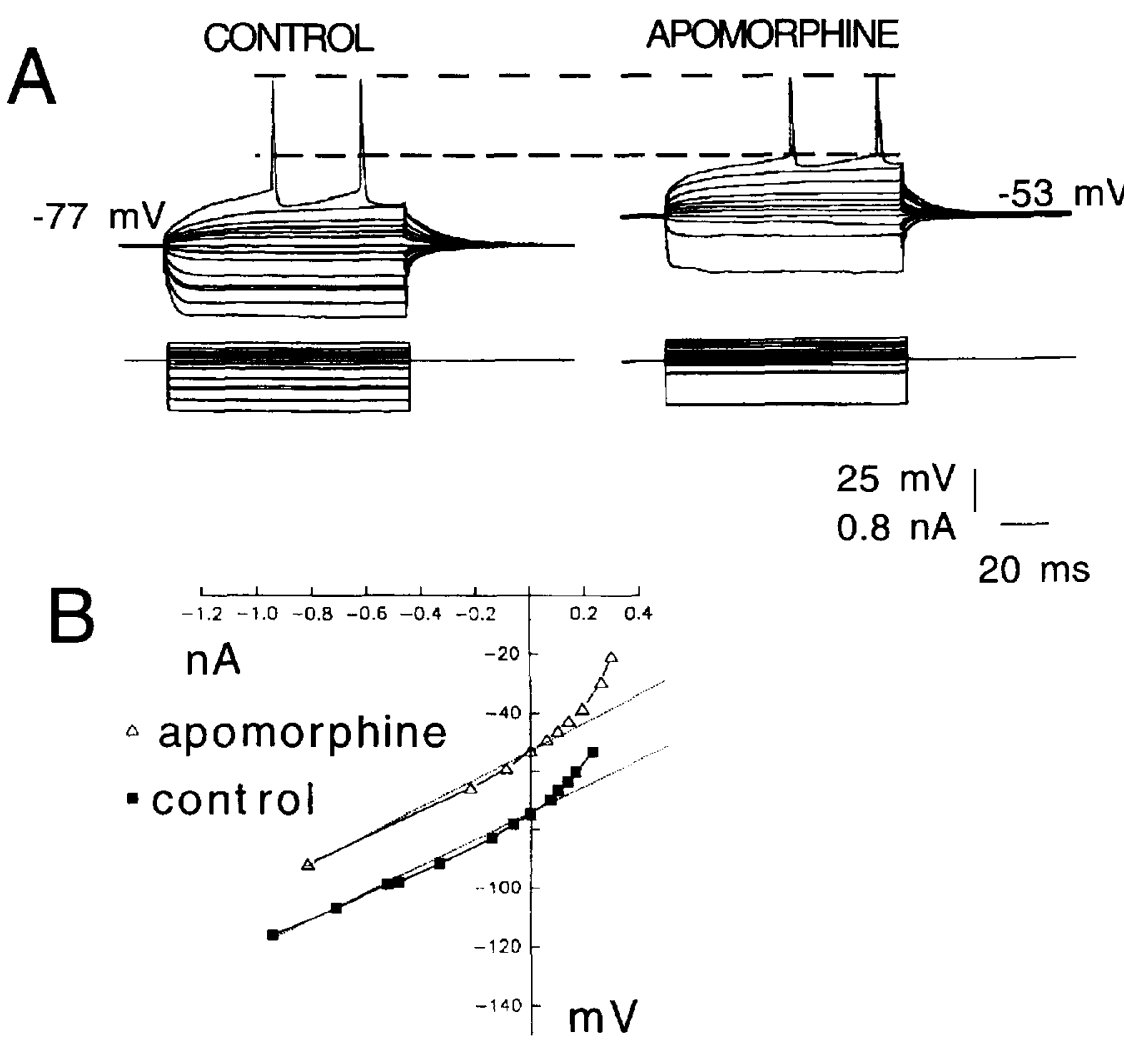

Figure 4. Apomorphine induces a membrane depolarization accompanied by an increase in the threshold for spike firing in accumbens neurons. (A) Overlay of voltage deflections (top) obtained in response to intracellular injection of current pulses (bottom) recorded from a shell neuron before (left) and during (right) apomorphine $(80 \mu \mathrm{M})$. Although apomorphine produced a $24 \mathrm{mV}$ depolarization of the membrane, the membrane threshold required to evoke spike discharge was shifted by $25 \mathrm{mV}$ in the depolarizing direction. The dashed line indicates the degree by which the membrane had to be depolarized during apomorphine administration to evoke spike discharge compared with that observed in control conditions for this neuron. The absence of a change in spike peak confirms that this response to apomorphine administration is not a consequence of nonspecific effects on the apparent membrane potential of the cell. (B) The current and voltage traces shown in $A$ are plotted to construct $I / V$ curves for this cell before (solid squares) and during (open triangles) apomorphine perfusion.

nists did not produce significant changes in the spike threshold membrane potential, significantly higher amplitudes of current injection were required to reach this spike threshold and evoke action potential discharge (Table 2).

These changes in cell excitability were also reflected in the firing rate-current ( $f l$ ) ratio measured during depolarization-induced spike discharge in these cells. Intracellular injection of current pulses at amplitudes in excess of threshold levels for evoking spike discharge induced the cell to fire a series of action potentials. Furthermore, progressive increases in the amplitude of current injected caused the cell to fire trains of spikes at progressively higher frequencies (Figure 7A, B). The firing frequency-current ratio was examined by plotting the inverse of the intervals between spikes (i.e., the instantaneous firing frequency) against the amplitude of the current injected (Figure 7C) and by assessing the resultant slope of this linear function ( $\mathrm{O}^{\prime}$ Donnell and Grace 1993b). Following the administration of apomor- phine the $f l$ ratio was reduced in every cell tested $(n=$ 4), with controls showing a slope of $175.3 \pm 39.3 \mathrm{~Hz} / \mathrm{nA}$ (126.5 to $216.7 \mathrm{~Hz} / \mathrm{nA}$ ) compared to $56.9 \pm 35.8 \mathrm{~Hz} / \mathrm{nA}$ ( 25 to $93.8 \mathrm{~Hz} / \mathrm{nA}$ ) following apomorphine administration $(t=3.5, p<.05$ paired $t$ test; Figure 7D).

\section{DISCUSSION}

\section{Apomorphine-Induced Changes in Passive Membrane Properties}

The electrophysiological characteristics of accumbens neurons reported here are similar to those described previously in the in vitro preparation in terms of their passive and active membrane properties and synaptic responses (Chang and Kitai 1986; Uchimura et al. 1986; Pennartz and Kitai 1991; O'Donnell and Grace 1993b, 1994). Perfusion of the accumbens slices with the nonselective dopaminergic agonist apomorphine induced a reversible depolarization in most of the neurons tested 

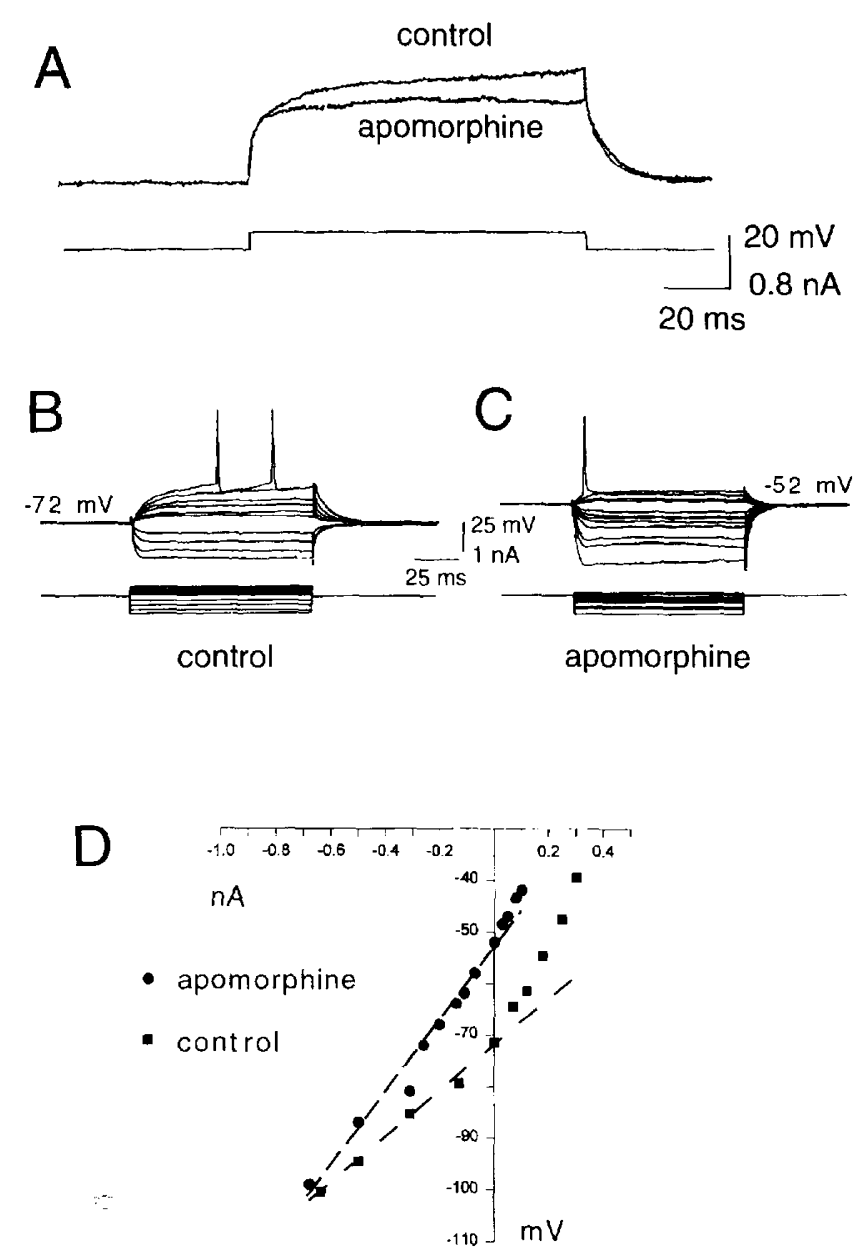

Figure 5. Apomorphine blocks the slow depolarization preceding spikes that is observed in most core cells. (A) Overlay of voltage deflections produced by a $0.2 \mathrm{nA}$ intracellular current injection into a core cell that had been perfused with physiological saline (control) and with apomorphine. (B) An example of the full range of membrane potential deflections (upper traces) observed in response to intracellular current injections (lower traces) in control conditions. (C) After apomorphine administration, the slow depolarization preceding spikes is no longer observed. (D) $I / V$ curve constructed from tracings in $B$ and $C$, showing the inward rectification with depolarizing current injections that corresponds to the slow depolarization in control conditions (squares) and the absence of such a rectification after apomorphine perfusion, as evidenced by the linearity of the plot in the depolarizing direction (circles). This cell was one of a subset of accumbens neurons that also exhibited an increase in input resistance in response to apomorphine administration.

in the core and shell regions of the accumbens without changing their input resistance or the time constant. This finding is consistent with the dopamine-induced depolarizations observed in accumbens neurons recorded in guinea pig slices (Uchimura et al. 1986) and with the depolarization induced by DA in the dorsal striatum using a similar preparation by some (Akaike et

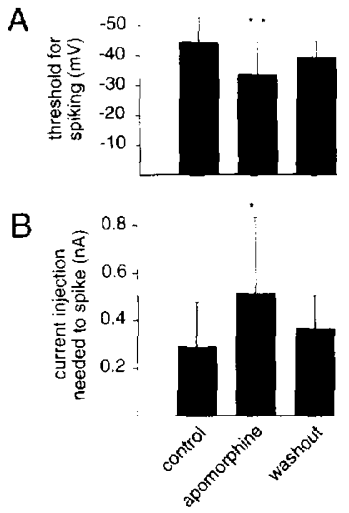

Figure 6. Apomorphine administration induces an increase in the threshold for action potential firing in accumbens neurons recorded in vitro. (A) The membrane potential at which spikes are elicited is shifted to a more depolarized value during apomorphine administration and exhibits a return toward control values during apomorphine washout. (B) The amount of current injection required to reach spike threshold for eliciting action potential firing is also significantly higher during perfusion with apomorphine. ${ }^{*} p<.005,{ }^{* *} p<.0001$, paired Student's $t$ test.

al. 1987), but not all (Calabresi et al. 1987), authors. In addition, $19 \%(5 / 26)$ of the cells treated with apomorphine showed a membrane depolarization along with an increase in input resistance. If these cells are analyzed as a separate group, the responses were found to have a reversal potential near $-95 \mathrm{mV}$, which is within the range of potentials typically associated with changes in potassium conductances. Therefore, it is possible that the stimulation of DA receptors in some accumbens cells may result in the inactivation of potassium conductances, as was proposed in experiments using acutely dissociated dorsal striatal cells (Kitai and Surmeier 1993). On the other hand, if the depolarization induced by apomorphine is produced in all cells independent of the changes in input resistance, it would suggest that the increase in resistance observed in these cells may be due to a decrease in a conductance that has a reversal potential near RMP, such as attenuation of a chloride conductance. Thus, the biophysical mechanisms underlying the changes observed remain to be elucidated.

\section{Apomorphine-Induced Changes in Firing Properties}

Despite the marked depolarization induced by apomorphine, the excitability of these cells with respect to spike discharge was substantially reduced. Under control conditions, intracellular current injection amplitudes of 0.3 $\mathrm{nA}$ were typically sufficient to trigger spike firing in accumbens neurons. However, when the slices were exposed to apomorphine the amplitude of current that 
A

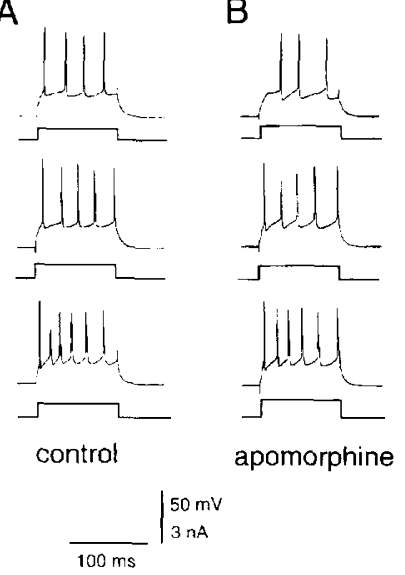

C

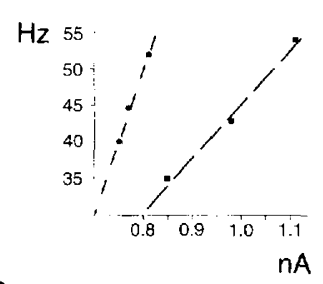

D

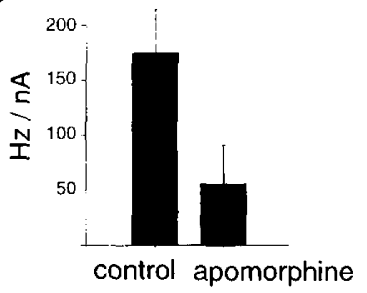

Figure 7. In the presence of apomorphine, significantly larger amplitudes of depolarizing current injection are required to evoke the same number of spikes as in controls. This is observed as a decrease in the firing frequency-current injection ratio in nucleus accumbens cells following apomorphine administration. (A, B) Three pairs of tracings showing changes in membrane potential (upper traces) in response to intracellular current injection (lower traces, square pulses) before $\mathbf{A}$ and after $\mathbf{B}$ administration of apomorphine (70 $\mu \mathrm{M})$. Increasing amplitudes of current injection result in a higher number of action potentials evoked per pulse. In the presence of apomorphine, larger amplitudes of current injections are required to evoke the same number of spikes as in control. (C) An fl plot constructed from data in A and B reveals the linear increase in frequency of firing with increasing current injection amplitude. Following apomorphine administration, the $f l$ plot exhibited a significantly smaller slope. (D) Bars show the mean \pm SD of the slopes of $f I$ ratios obtained before and after apomorphine administration in all four cells tested, revealing a significant decrease in cell excitability after apomorphine administration.

was required to evoke spike discharge was significantly higher. This decrease in excitability was not simply a consequence of increased membrane conductance, since: (1) apomorphine did not decrease the input resistance in any of the accumbens cells tested; and (2) the membrane potential corresponding to spike threshold shifted to significantly more depolarized levels. This effect, which was observed in neurons from both the core and shell regions, is similar to what has been reported in slices of the dorsal striatum (Akaike et al. 1987; Rutherford et al. 1988) and the human caudate nucleus (Cepeda et al. 1994). In addition to increasing the threshold for spike discharge, apomorphine also attenuated the ability of accumbens cells to fire high-frequency trains of spikes. Thus, perfusing the cells with apomorphine reduced the slope of the $f l$ ratio: following treatment with apomorphine there is a smaller increase in firing frequency with increasing amplitudes of current injection. Thus, the activation of DA receptors results in a reduced 
number of action potentials evoked in response to a predetermined amplitude of membrane depolarization.

The inhibitory nature of apomorphine on these neurons was further reflected in the reversible blockade of the slow depolarization preceding spike discharge that was observed in a majority of neurons in the core region. We have recently demonstrated that the prespike slow depolarization is a calcium-dependent event ( $\mathrm{O}^{\prime}$ Donnell and Grace 1993b). Thus, it is possible that, at least in some core neurons, DA receptor activation leads to a decrease in calcium conductances in accumbens neurons in a manner similar to that reported for DA effects on pituitary melanotrophs (Williams et al. 1990).

\section{Activation of Both $D_{1}$ and $D_{2}$ Receptors is Required to Elicit the Decrease in Accumbens Neuron Excitability}

Although we have previously shown that the apomorphine-induced decrease in excitatory postsynaptic potential (EPSP) amplitude could be observed with perfusion of quinpirole (O'Donnell and Grace 1994), few of the effects of apomorphine on cell excitability could be mimicked by the selective agonists SKF 38393 or quinpirole when administered alone. Thus, the changes in membrane potential or spike threshold occurring with apomorphine were not reproduced by the selective agonists when they were administered independently. In contrast, the combined administration of both $\mathrm{D}_{1}$ and $\mathrm{D}_{2}$ agonists together produced the same effects as apomorphine with respect to the increase in amplitude of intracellular current injection required to elicit action potential firing, although the increase in spike threshold membrane potential produced by combined $\mathrm{D}_{1} / \mathrm{D}_{2}$ agonist administration was smaller in amplitude and did not reach statistical significance when the responses are averaged across the population of cells recorded. This suggests that a synergistic coactivation of both DA receptor subtypes may be necessary to induce the decrease in cell excitability that is observed with apomorphine administration. Although the mechanism behind this synergistic action is not known, a synergistic coactivation of $\mathrm{D}_{1}$ and $\mathrm{D}_{2}$ dopamine receptors has been proposed to modulate striatal cell excitability by suppression of $\mathrm{Na}^{+} / \mathrm{K}^{+}$ATPase activity (Bertorello et al. 1990).

\section{Conclusions and Functional Implications}

Although apomorphine administration typically results in the depolarization of accumbens cell membranes, it is apparent that its net effect on accumbens cell spike discharge is inhibitory. This inhibition is observed as: (1) an increase in the threshold membrane depolarization required to trigger spike firing; (2) a higher amplitude of depolarizing current injection required to reach threshold for eliciting spike discharge; (3) a reduced slope in the firing frequency-current injection ratio; and (4) a reduction in the slow depolarization preceding spikes that is typically present in core but not shell neurons. In addition, we have recently shown that $\mathrm{D}_{2} / \mathrm{D}_{3}$ receptor activation induces a reduction in the amplitude of EPSPs evoked by cortical afferent stimulation (O'Donnell and Grace 1994). Thus, despite its ability to depolarize the membrane of accumbens cells, the action of apomorphine in decreasing evoked excitation and its ability to decrease cell excitability should result in a potent inhibition of accumbens cell firing. In contrast, although $D_{1}$ and $D_{2}$ agonists combined mimic the ability of apomorphine to decrease cell excitability, these drugs did not induce a depolarization of the membrane potential in the majority of the neurons tested. Because apomorphine has a high affinity for all DA receptor subtypes (Sokoloff et al. 1992), SKF38393 binds to both $D_{1}$ and $D_{5}$ receptors, and quinpirole has a high affinity for $D_{2}$ and $D_{3}$ (but not $D_{4}$ ) receptors, a possible interpretation is that the depolarizing effect may be due to the activation of $\mathrm{D}_{4}$ receptors. However, the distribution of $\mathrm{D}_{4}$ receptors within the accumbens appears to be sparse (Van Tol et al. 1991), and furthermore our preliminary results show that the apomorphine-induced depolarization in accumbens neurons is not altered by administration of the potent $\mathrm{D}_{4}$ antagonist (Van Tol et al. 1991) clozapine (unpublished observation).

One possible implication of the changes in cell excitability observed here is that the activation of DA receptors in the accumbens results in a decrease in the background level of accumbens cell firing. Because DA has been proposed to also act via "volume transmission" (Fuxe and Agnati 1991), some of its effects are likely to occur over a large distance rather than in a highly localized mode. Furthermore, in addition to lowering accumbens cell postsynaptic excitability, DA has been shown to induce a decrease in the amplitude of cortically evoked EPSPs in accumbens cells (O'Donnell and Grace 1994) and in the degree of electrotonic transmission (observed as a decrease in the incidence of dye coupling) among neurons in the core region of the accumbens (O'Donnell and Grace 1993a). Taken together, each of these actions of DA would be expected to reduce the background levels of spontaneous spike discharge in a population of accumbens cells, resulting in an increased signal-to-noise ratio for cortical throughput within the accumbens. Our in vivo studies have shown that the accumbens neurons that exhibit a bistable membrane potential are activated by cortical afferents only when the cells are first put into the depolarized state by activation of hippocampal inputs (O'Donnell and Grace 1995). Therefore, in the absence of DA one might predict that the cortical inputs alone may be sufficient to induce accumbens cell firing; however, in the presence of DA, both baseline firing and the cortexinduced excitation of accumbens cells should be attenu- 
ated. Under these conditions, the requirement for coactivation of hippocampal afferents to enable corticoaccumbens throughput to occur would be even more stringent. Indeed, this could represent the cellular mechanism underlying the proposed role of DA in exerting a focusing effect on information flow in the striatum (Schultz 1989).

\section{ACKNOWLEDGMENTS}

We wish to thank Mr. Mark Antkowiak for his excellent technical assistance and Mr. Brian Lowry for developing the computer program Neuroscope that was used for data acquisition and analysis. Supported by USPHS MH42217, MH45156, MH01055 (A.A.G.), and Tourette Syndrome Association $\left(\mathrm{PO}^{\prime} \mathrm{D}\right)$. Part of this work has been presented in $\mathrm{ab}-$ stract form (Grace and O'Donnell, 1995).

\section{REFERENCES}

Akaike A, Ohno Y, Sasa M, Takaori S (1987): Excitatory and inhibitory effects of dopamine on neural activity of the caudate nucleus neurons in vitro. Brain Res 418:262-272

Alexander GE, Crutcher MD (1990): Functional architecture of basal ganglia circuits: Neural substrates of parallel processing. Trends Neurosci 13:266-271

Alheid GF, Heimer L (1988): New perspectives in basal forebrain organization of special relevance for neuropsychiatric disorders. The striatopallidal, amygdaloid, and corticopetal components of substantia innominata. Neuroscience 27:1-39

Bertorello AM, Hopfield JF, Aperia A, Greengard P (1990): Inhibition by dopamine of $\left(\mathrm{Na}^{+}+\mathrm{K}^{+}\right)$ATPase activity in neostriatal neurons through $\mathrm{D}_{1}$ and $\mathrm{D}_{2}$ dopamine receptor synergism. Nature 347:386-388

Brown JR, Arbuthnott GW (1983): The electrophysiology of dopamine $\left(\mathrm{D}_{2}\right)$ receptors: A study of the actions of dopamine on corticostriatal transmission. Neuroscience 10:349-355

Calabresi P, Mercuri NB, Stanzione P, Stefani A, Bernardi G (1987): Intracellular studies on the dopamine-induced firing inhibition of neostriatal neurons in vitro: Evidence for $D_{1}$ receptor involvement. Neuroscience 20:757-771

Cepeda C, Walsh JP, Peacock W, Buchwald NA, Levine MS (1994): Neurophysiological, pharmacological and morphological properties of human caudate neurons recorded in vitro. Neuroscience 59:89-103

Chang HT, Kitai ST (1986): Intracellular recordings from rat nucleus accumbens neurons in vitro. Brain Res 366:392396

Chiodo LA, Bunney BS (1983): Typical and atypical neuroleptics: Differential effects of chronic administration on the activity of A9 and A10 midbrain dopaminergic neurons. J Neurosci 3:1607-1619

Connor JD (1970): Caudate nucleus neurones: Correlation of the effects of substantia nigra stimulation with iontophoretic dopamine. J Physiol 208:691-703
De France JF, Sikes RW, Chronister RB (1985): Dopamine action in the nucleus accumbens. J Neurophysiol 54: 1568-1577

Fuxe K, Agnati L (1991): Two principal modes of electrochemical communication in the brain: Volume versus wiring transmission. In Fuxe K, Agnati L (eds), Volume Transmission in the Brain: Novel Mechanisms for Neural Transmission. New York, Raven, pp 1-9

Grace AA (1991): Phasic versus tonic dopamine release and the modulation of dopamine system responsivity: A hypothesis for the etiology of schizophrenia. Neuroscience 41:1-24

Grace AA, O'Donnell P (1995): Dopamine inhibition of nucleus accumbens cell activity occurs via two independent mechanisms: Evidence from in vivo and in vitro intracellular recordings. Soc Neurosci Abstr 21:1659

Groenewegen HJ, Becker NEHM, Lohman AHM (1980): Subcortical afferents of the nucleus accumbens septi in the cat, studied with retrograde axonal transport of horseradish peroxidase and bisbenzimid. Neuroscience 5: 1903-1916

Guyenet PG, Aghajanian GK (1978): Antidromic identification of dopaminergic and other output neurons of the rat substantia nigra. Brain Res 150:69-84

Heimer L, Zahm DS, Churchill L, Kalivas PW, Wohltmann C (1991): Specificity in the projection patterns of accumbal core and shell in the rat. Neuroscience 41:89-125

Herrling PL, Hull CD (1980): Iontophoretically applied dopamine depolarizes and hyperpolarizes the membrane of cat caudate neurons. Brain Res 192:441-462

Hu X-T, Wang RY (1988): Comparison of effects of $D_{1}$ and $D_{2}$ dopamine receptor agonists on neurons in the rat caudate putamen: An electrophysiological study. J Neurosci $8: 4340-4348$

Kitai ST, Surmeier DJ (1993): Cholinergic and dopaminergic modulation of potassium conductances in neostriatal neurons. In Narabayashi T, Nagatsu N, Yanagisawa N, Mizuno N (eds), Advances in Neurology, vol 60. New York, Raven, pp. 40-52

Kitai ST, Sugimori H, Kocsis J (1976): Excitatory nature of dopamine in the nigro-caudate pathway. Exp Brain Res 24:351-363

Lavín A, Grace AA (1994): The modulation of mediodorsal and dorsal thalamic nuclei by the ventral pallidum: Its role in the regulation of thalamocortical activity in the basal ganglia. Synapse 18:104-127

McLennan H, York DH (1967): The action of dopamine on neurones of the caudate nucleus. J Physiol 189:393-402

Mogenson GJ, Yang CR, Yim CY (1988): Influence of dopamine on limbic inputs to the nucleus accumbens. Ann NY Acad Sci 537:86-100

O'Donnell P, Grace AA (1993a): Dopaminergic modulation of dye coupling between neurons in the core and shell regions of the nucleus accumbens. J Neurosci 13:3456-3471

O'Donnell P, Grace AA (1993b): Physiological and morphological properties of accumbens core and shell neurons recorded in vitro. Synapse 13:135-160

O'Donnell P, Grace AA (1994): Tonic $\mathrm{D}_{2}$-mediated attenuation of cortical excitation in nucleus accumbens neurons recorded in vitro. Brain Res 634:105-112 
O'Donnell P, Grace AA (1995): Synaptic interactions among excitatory afferents to nucleus accumbens neurons: Hippocampal gating of prefrontal cortical input. J Neurosci 15:3622-3639

Ohno Y, Sasa M, Takaori S (1987): Coexistence of inhibitory dopamine $D_{1}$ and excitatory $D_{2}$ receptors on the same caudate nucleus neurons. Life Sci 40:1937-1945

Paxinos G, Watson C (1986): The Rat Brain in Stereotaxic Coordinates. Sydney, Academic Press

Pennartz CMA, Kitai ST (1991): Hippocampal inputs to identified neurons in an in vitro slice preparation of the rat nucleus accumbens: Evidence for feed-forward inhibition. J Neurosci 11:2838-2847

Pennartz CMA, Dolleman-van der Weel MI, Kitai ST, Lopes da Silva FH (1992a): Presynaptic dopamine $D_{1}$ receptors attenuate excitatory and inhibitory limbic inputs to the shell region of the rat nucleus accumbens. J Neurophysiol 67:1325-1334

Pennartz CMA, Dolleman-van der Weel MI, Lopes da Silva FH (1992b): Differential membrane properties and dopamine effects in the shell and core of the rat nucleus accumbens studied in vitro. Neurosci Lett 136:109-112

Rutherford A, García Muñoz M, Arbuthnott GW (1988): An after hyperpolarization recorded in striatal cell "in vitro": Effect of dopamine administration. Exp Brain Res 71:399-405

Schultz W (1989): Neurophysiology of basal ganglia. In Calne DB (ed), Handbook of Experimental Pharmacology, Vol 88. Berlin, Springer-Verlag, pp 1-45

Sesack SR, Deutch AY, Roth RH, Bunney BS (1989): Topographical organization of the efferent projections of the medial prefrontal cortex in the rat: An anterograde tracttracing study with Phaseolus vulgaris leucoagglutinin. J Comp Neurol 290:213-242
Snyder SH (1973): Amphetamine psychosis: A model of schizophrenia mediated by catecholamines. Am J Psychiatry 130:61-67

Sokoloff P, Martres MP, Giros B, Bouthenet ML, Schwartz JC (1992): The third dopamine receptor $\left(D_{3}\right)$ as a novel target for antipsychotics. Biochem Pharmacol 43:659-666

Uchimura N, Higashi H, Nishi S (1986): Hyperpolarizing and depolarizing actions of dopamine via $D_{1}$ and $D_{2}$ receptors on nucleus accumbens neurons. Brain Res 374:368-372

Uylings HBM, van Eden CG (1990): Qualitative and quantitative comparison of the prefrontal cortex in rat and in primates, including humans. Progr Brain Res 85:31-62

Van Tol HHM, Bunzow JR, Guan HC, Sunahara RK, Seeman P, Niznik HB, Civelli O (1991): Cloning of the gene for a human $D_{4}$ receptor with high affinity for the antipsychotic clozapine. Nature 350:610-614

White FJ, Wang RY (1986): Electrophysiological evidence for the existence of both $D_{1}$ and $D_{2}$ dopamine receptors in the rat nucleus accumbens. J Neurosci 6:274-280

Williams PJ, MacVicar BA, Pittman Q (1990): Synaptic modulation by dopamine of calcium currents in rat pars intermedia. J Neurosci 10:757-763

Woodruff GN, McCarthy PS, Walker RJ (1976): Studies on the pharmacology of neurones in the nucleus accumbens of the rat. Brain Res 115:233-242

Young WS, Alheid GF, Heimer L (1984): The ventral pallidal projection to the mediodorsal thalamus: A study with fluorescent retrograde tracers and immunohistofluorescence. J Neurosci 4:1626-1638

Záborszky L, Alheid GF, Beinfeld ML, Eiden LF, Heimer L, Palkovits M (1985): Cholecystokinin innervation of the ventral striatum: A morphological and radioimmunological study. Neuroscience 14:427-453 